cia en el nombre o la fluctuación en el verbo) atribuidos por los gramáticos escolásticos a cada parte de la oración ${ }^{12}$.

Aunque Nebrija no lo declara explícitamente nunca, podemos suponer que su concepto de la "manera de significar" es doble, y abarca tanto el criterio estrictamente semántico cuanto el funcional. Al emplear dicha expresión, nunca trata de establecer una distinción clara entre el significado metafísico absoluto de una forma y su significado sintáctico ocasional. Las categorías que usa en sus ejemplos para mostrar la posibilidad de que una forma determinada tenga diversas maneras de significar son las que podían establecerse, no sólo de acuerdo con cualquier criterio formal, sino también de acuerdo con sus respectivos significados (nombre, verbo ${ }^{13}$, pronombre y nombre participial infinito) o con su diversa función (artículo, conjunción y adverbio).

La mayor originalidad de Nebrija en este punto radica, por consiguiente, no en su clasificación de las partes del discurso, sino de manera especial en su criterio de clasificación semántico-funcional, consecuencia de su original interpretación de las definiciones tradicionales de la escolástica.

University of California, Los Angeles.

JUDITH SENIOR

\title{
DOS ROMANCES FRONTERIZOS EN LA TRADICIÓN SEFARDÍ ORIENTAL
}

En las colecciones de romances hasta ahora publicadas, casi no hay ejemplos de romances fronterizos procedentes de la tradición sefardi del Mediterráneo oriental. En cambio, se conocen bastantes romances de esa clase conservados en la tradición marroquí ${ }^{1}$. A la superioridad de esta última se refiere Menéndez Pidal cuando dice: "Ella conserva, a la vez que el arcaísmo distintivo de los judíos orientales, un mayor carácter histórico español que esos otros han perdido. Ciertos romances heroicos del Cid y de Bernardo, algunos fronterizos, varios moriscos, son frecuentes en Tánger, en Tetuán, en Alcazarquivir y en Larache, cuando

12 Cf. Charles Thurot, Notices et extraits de divers manuscrits latins pour servir à l'histoire des doctrines grammaticales au moyen âge, Paris, 1868, pp. 148 ss. X, en forma resumida, R. H. Robins, op. cit., pp. 81 ss.

${ }^{13}$ En la definición del verbo que da en su gramática española, Nebrija omite toda alusión a su significado. Sin embargo, en su gramática latina recoge la valoración semántica tradicional: el verbo expresa acción y pasión: “¿Qué cosa es verbo? Parte de la oración que se declina con modos y tiempos sin casos; y significación tiene de hacer y padecer" (p. 141).

1 Véanse las colecciones de $\mathrm{R}$. Menéndez Pidal, "Catálogo del romancero judíoespañol", Cultura Española, 4 (1906), 1045-1077, y 5 (1907), 161-199 (reimpreso, con abreviación de algunos textos, en El Romancero, Teorias $e$ investigaciones, Madrid, 1928, y en Los romances de América, Buenos Aires-México, 1948); M. OrTegA, Los hebreos en Marruecos, Madrid, 1919; P. BÉNıchou, "Romances judeo-españoles de Marruecos", RFH, 6 (1944), 36-76, 105-138, 255-279, 313-381; y A. Larrea PALAcín, Romances de Tetuán, 2 ts., Madrid, 1952. Recogen versiones marroquíes del Alcaide de Alhama (véase infra, nota 8), de Abenámar (Primavera y flor [abreviaremos en adelante "W.'], 78a; Catálogo, núm. 10), del Romance de Portocarrero (Catálogo, núm. 11; Bénichou, núm. 62) y del de Garcilaso de la Vega (W., 93; 
hoy ni en España ni en Oriente nadie los recuerda por tradición oral..." (Romancero hispánico, t. 2, p. 335).

No es absoluta, sin embargo, la ausencia de romances fronterizos en la tradición oriental ${ }^{2}$. En el Romancero sefaradi publicado en Israel en 1956 por Moshe Attias se incluye ya un romance fronterizo recogido en Salónica ${ }^{3}$. Damos a conocer ahora dos breves romances de esa clase, que hemos oído en boca de los sefardíes oriundos de los Balcanes emigrados a la costa occidental de los Estados Unidos ${ }^{4}$.

-I al buen moro $i$ al buen moro, el de la barva enveyutada
vos mandó ayamar el reyes $i$ que vos quiere una palavra.
I que él vos quiere una palayra, tan secreta $i$ tan ortala.
Cortarvos quiere la cavesa i metervos quiere a la almuxama.
-I anda, dezilde al buen reyes i que yo no le culpi nada.
El [léase Yo] pedria una ija donzeya, tan querida $i$ tan amada.

Ortega, p. 252; BÉnichou, núm. 63; Larrea, núm. 8). Para la música de este último romance, véase Menéndez Pidal, Romancero hispánico, Madrid, 1953, t. 1, p. 398 En la tradición sefardí de Marruecos se encuentran también unos versos de $L a$ pérdida de Antequera (W., 75), sirviendo de introducción a un romance de Bernardo del Carpio. Publica Menéndez Pidal unas doce versiones de este fragmento, procedentes de Tánger, Tetuán, Alcazarquivir, Larache y Buenos Aires (de origen marroquí) en el Romancero tradicional de las lenguas hispanicas, Madrid, 1957, t. 1, pp. $177^{-1} 84$, núms, $1 c-1 n$. Incluyen estas versiones las de Bénichou (núm. 61) y Larrea (núms. I y $1 b$ ) y la que publicó Menéndez Pidal en su Catálogo con el núm. 8, que corresponde al núm. id del Romancero tradicional.

2 También advierte esto Menéndez Pidal en su Romancero hispánico. Refiriéndose al primero de los romances que ahora publicamos, observa que ha subsistido "hasta hoy entre los judios de Oriente y de Marruecos" (t. 1, p. 143).

${ }^{a}$ Moshe ATtuas, Romancero sefaradi: Romanzas y cantes populares en judeo-español, Instituto Ben-Zewi, Universidad Hebrea, Jerusalén, 1956. Sobre este romance, véase infra, nota 5 .

\& En agosto de 1957 emprendimos la búsqueda de romances tradicionales en la comunidad judeo-española de Los Angeles. En el verano de 1958 nos trasladamos a San Francisco y Seattle con el mismo propósito. El presente artículo anticipa la publicación extensa de los textos y la música de todos los romances que hemos ido recogiendo. Un bosquejo preliminar de la colección, y noticias sobre algunos romances más que se conservan en estas comunidades, se encontrarán en nuestro artículo "Hispanic balladry among the Sephardic Jews of the West Coast", que se publicará en $\boldsymbol{W F}$.

${ }^{5}$ Por razones tipográficas ajustamos nuestra transcripción a las normas de la ortografía tradicional. Las siguientes letras tienen valor especial: $v$ : labiodental frica. tiva sonora; $z$ : alveolar fricativa sonora; $x$ : palatal fricativa sorda; $j$ : palatal fricativa sonora; $g$ (ante $e, i$ ), $g^{i}$ (ante $a, o, u$ ): palatal africada sonora; $h$ : velar fricativa sorda. En la publicación completa de nuestra colección haremos una transcripción fonémica. Este romance nos lo cantó la Sra. Ester Varsano Hassid, de Salónica, en Van Nuys, California, el 20 de agosto de 1957. Al cantar, repitió el segundo hemistiquio de cada verso, con excepción del 2 y del 6 . Lo cantó como romance independiente, mientras que la variante recogida por Atrias se da como continuación de una versión de las Almenas de Toro (Romancero sefaradi, núm. 2, vs. 3558 ). En los romances de Salónica, la forma reyes 'rey' (vs. 2, 5) ocurre regularmente cuando la palabra siguiente empieza con vocal anterior. Nuestra informante interpreta ortala 'decisiva, urgente'. Quizá refleje el turco örtülü 'covered; concealed; obscure [of speech]' (H. C. Hony, A Turkish-English dictionary, Oxford, 1957), aunque el vocalismo presenta graves dificultades. El sentido de almuxama tampoco parece claro. Nuestra recitadora lo define como 'un sitio para matar a personas o animales; un 
Nuestro texto, procedente de Salónica, representa una variante algo abreviada del romance núm. 2 de la colección de Attias. Como éste afirma, deriva del "sentido y antiguo romance" del Alcaide de Alhama, impreso en 1595 en la Historia de los vandos de los Zegries de Ginés Pérez de Hita ${ }^{6}$. El romance antiguo, que tenía unos 25 versos, ha sido radicalmente abreviado en estas versiones sefardíes. Sólo se conservan los rasgos más esenciales de la denuncia y respuesta del alcaide. Se han eliminado todos los detalles que explican las circunstancias de la acción. Han desaparecido los "caballeros y hombres buenos, / los que regís a Granada" que en el texto antiguo acusan al alcaide, y no se sabe a quién o a quiénes dirige la palabra el protagonista. La misma pérdida de Alhama, así como la ausencia del alcaide en Antequera, claramente explicadas en la versión del siglo xvI, se han fundido en una vaga frase en la versión de Attias ("de cuando hueron las guerras"), y faltan

matadero'. La variante de Attias, una muřšáma, no resulta del todo satisfactoria

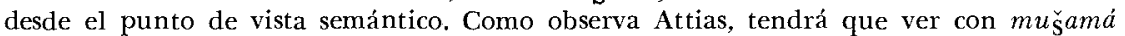
o $m u$ ธ̌ama 'toile cirée' (véanse otros ejemplos en C. M. CRews, Recherches sur le judéo-espagnol dans les pays balkaniques, Paris, 1935, p. 259; S. I. CrérézLr, Nouveau petit dictionnaire judéo-espagnol-français, Jerusalén, 1898-99, p. 141; A. DANON, "Essais sur les vocables turcs dans le judéo-espagnol", Keleti Szemle, 5, 1904, 119 ; E. Gménez Carallero, "Monograma sobre la juderia de Escopia", ROcc, 27, 1930, 373). El jud.-esp. posee esta voz en común con las demás lenguas balcánicas

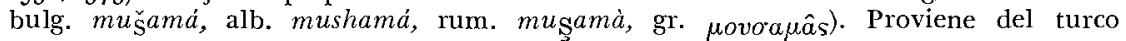
$m u_{\text {Ş}} a m b a$ (a su vez de origen árabe: $m u_{\text {S}} a m m a$ ). Literalmente almuxama significaría en turco 'hule rojo', cosa que en el romance tiene muy poco sentido. Más bien representará una forma corrompida de "Alhambra", que aparece en el romance del siglo xvr del cual deriva el texto sefardí. El topónimo queda ya eliminado en la versión del Cancioneiro musical e poético da Biblioteca Públia Hortênsia: "Y ponella en alcaçoua" (eđ. M. Joaquim, Coimbra, 1940, p. 158). Nuestro v. 6 debe leerse: "Yo pedría...", como reza la versión de Attias. El texto de Attias ofrece estas variantes (seguimos nuestra propia numeración y omitimos algunas indicaciones gráficas peculiares de la transcripción de Attias): $1 a$ El b. $\mathrm{m}$. el b. $\mathrm{m}$. I| $2 a$ el buen rey $\|$ $2 b$ falta i $\| 3^{a}$ Qué palabra era ésta $\| 3^{b}$ tan notada $\| 4^{b}$ echarla en una mur šáma \| $5^{a}$ falta I, rey $\| 5^{b}$ que yo no lo cuipo nada II Después de nuestro v. 5 sigue el texto de Attias: de cuando hueron las guerras / pedrí mi honra y mi fama; // pedrí hijos y mujer / y una cosa muy amada. // pedrí una hija doncella / oue otra no había en Grenada; termina el texto con cuatro versos en i-a: pedrí mil y quinientos mulinos / que molían noche y día, // quinientos molían oro / y los quinientos plata fina // quinientos molían perla / que para el rey pertenecían. // Ya se parte el buen moro, / ya se parte, ya se iba. Hay aquí una contaminación evidente; cf. el "Romance de Paris, del juicio que dio...", Cancionero de romances sin año, fol. 195 $\mathrm{r}^{\circ}-\mathrm{v}^{\circ}$ : “... mil y quinientos molinos/que d'él [el río] muelen noche y día: // quinientos muelen canela / y quinientos perla fina // y quinientos muelen trigo / para sustentar la vida; // todos eran del gran rey [Príamo] / que a los reyes precedía..."

${ }^{8}$ Ed. P. Blanchard-Demouge, Madrid, 1913, t. 1, p. 256 . Corresponde a W., $84^{a}$ y al núm. 1062 del Romancero general de Durán, aunque hay ligeras diferencias sintácticas entre éstos y el texto de Blanchard-Demouge. Otra versión más breve (W., 84; Durán, 1061), con asonante $i$-a, que aparece ya en el Cancionero de romances de $155^{\circ}$, termina como las versiones sefardíes orientales con la pérdida de la familia del alcaide. Menéndez Pelayo y otros críticos opinan que la forma en $a ́ a$ "debe de ser una paráfrasis" de la del Cancionero de $155^{\circ}$ en i-a (Antologia de poetas líricos castellanos, Madrid, 1944, t. 7, p. 126). Menéndez Pidal, cuva opinión nos parece más convincente, observa que el romance en $\dot{a}-a$ "es la forma más popular, más cantada en el siglo xvi, ...pero al lado de ella circuló otra forma contrahecha en ia" (Romancero hispánico, t. 1, pp. 143-144 y nota 12.1). 
por completo en la abreviada versión nuestra. Fuera de la mención de "Grenada" en la versión de Attias, los nombres propios se han eliminado o han sufrido alteración radical (por ejemplo, almuxama), como a menudo sucede, sobre todo en la tradición sefardí oriental' ${ }^{7}$ En las dos versiones judeo-españolas, el romance queda trunco; no se menciona el fallido rescate y conversión de la hija al cristianismo, y falta el trágico desenlace en que es decapitado el alcaide; queda, pues, envuelto en misterio todo el proceso de la narración. Esta nota de tragedia inexplicada, que coincide con una de las versiones del siglo xvi, merece señalarse entre las abreviaciones acertadas que suele producir la tendencia fragmentarista del Romancero tradicional ${ }^{8}$.

\section{II}

De la giuma sale el moro, de la giuma al mediodia,
con trezientos cavayeros se yeva por compañia.
I no es por compañia, ni por favor que tenia,
sino que diga la gente: $\quad$ - Oh, qué gran cavayeria!
Lo que él arrastra por embaxo, sien mil proves ricos fazia;
la toca que él yevava, lavrada a la maravia;

${ }^{7}$ La toponimia peninsular, bien conservada en el romancero de Marruecos, se reduce radicalmente en la tradición oriental, donde sólo son frecuentes las referencias a Aragón, Portugal, Granada y Sevilla. La onomástica también parece haber sufrido más en Oriente que en Marruecos. Compárense un par de ejemplos: En las diez versiones marroquíes publicadas del romance de las Hermanas reina y cautiva (Catálogo, 48) se conserva el nombre tradicional, Blancaflor, mientras que en los ocho textos orientales que conocemos sufre múltiples cambios: Sanjoeli, Sanjigüela, Sangíugale (en una versión nuestra inédita), Lifanta, Vida y Marqueta (en tres versiones). Las versiones marroquíes de los Amantes perseguidos (Catálogo, 55) conservan generalmente el nombre del Conde Niño, mientras éste se convierte en el Conde Alemán o Alemar en Salónica o queda anónimo ("un mansevico") en Turquía y en las dos versiones distintas que existen en la tradición de Rodas. Entre otras muchas versiones impresas de los Amantes perseguidos, véanse los cinco textos representativos que acaba de publicar A. Hemsi, "Sur le folklore séfardi", JS, I959, núm. 18, 794-795. De los catorce textos del romance de Don Bueso y su hermana (Catálogo, 49) que hemos recogido procedentes de la isla de Rodas, sólo tres conservan el nombre Don Bezo, considerado como un solo apellido: Dumbezo. Otra versión que tenemos de Salónica le llama Andaneto, y queda anónimo en versiones de Mármara y Constantinopla. De los siete textos orientales de este romance ya publicados, sólo dos conservan el nombre tradicional (A. DANon, REI, 32, p. 272, núm. 18, Dumbélo; y Atrias, núm. 1, Don Bueso [léase Buezo]). La única versión completa auténticamente marroquí hasta ahora publicada (LARREA, núm. 58) ofrece Don Güeso. Bénichou da noticia de otro sefardí de Marruecos en que el héroe se llama Huezzo $(R F H, 6,123)$.

${ }^{8}$ Véanse ejemplos en MenÉndez Pidal, Flor nueva de romances viejos, Buenos Aires-México, 1946, pp. 26-29, y Romancero hispánico, 1, 71-75. El mismo romance del Alcaide de Alhama subsiste en la tradición sefardí de Marruecos. Hay versiones de Tánger (Catálogo, 9) y Tetuán (LarreA, núm. 10) que se conservan mucho más completas y próximas al texto del siglo xvi y mantienen con relativa fidelidad muchos detalles que faltan en los textos orientales: la pérdida de Alhama (transformada en Alamba o Alámbar); los acusadores del alcaide, convertidos en aburguesados "mercaderes y hombres ricos, / los que viven en Granada" (LARREA); y el rescate y conversión de la hija. Por otra parte, no se habla del viaje a Antequera ni de la muerte del alcaide, y la mención de la Alhambra se sustituye por el verso "y se la enfielen en la lansa" (LarreA) o "y se la enfilen en lanza" (Catálogo). Compárese la variante que recoge Attias (p. 63, nota 4): "puntarla en la su lanza". 
que se la lavró esta toca Xerifá, la su amiga;

Xerifá que está en altas torres, las más altas que Turquia9.

Hemos recogido hasta ahora doce textos de este romance, todos ellos procedentes de Rodas. No figura esta versión "rodesli" en ninguna de las colecciones impresas. Sin embargo, el mismo romance se conoce o se conocía en Salónica, donde se cantaba, no a la manera de Rodas como canción autónoma, sino como continuación de un romance de Miliselda y Don Gaifero. Así aparece entre los romances recogidos por Carlos Coello e impresos por Menéndez Pelayo en el suplemento a la Primavera y flor. Attias también recoge un texto semejante, fundido de igual modo con el romance de Miliseld $a^{10}$. Aunque salta a la vista la incoherencia de los dos asuntos reunidos así en una sola narración romancística ${ }^{11}$,

- En Los Ángeles nos cantaron este romance las Sras. Perla Galante, Sol Cohen, Rachel Tarica, Leah Huniu, Rebeca Peha, Leonor Halfon, Estrella Mayo y Rebeca Levi. La Sra. Victoria Hazan Kassner nos facilitó una versión escrita en letras hebreas que figura en un antiguo manuscrito, cuyo caudal romancístico publicaremos íntegramente en otra ocasión. En Seattle recogimos versiones cantadas por las Sras. Rosa Alhadeff, Tamar Tarica y Rosa Franco. El texto que ofrecemos es el de la Sra. Galante. Suplimos el v. 8 de acuerdo con dicho manuscrito. Éste y las demás versiones orales ofrecen las siguientes variantes: i $b$ a $\mathrm{m}$., en $\mathrm{m}$. $\| 2 a$ sincuenta, quinientos $\| 2 b$ se yevan, se yevava, se los yeva, los yeva $\| 3^{a}$ no era, non era, no se los yeva por copañía [sic] $\| 3^{b}$ ni por favor que (él) quería, sino por bafor que quería (falta $4^{a b}$ ), sino por grande cavayería $\| 4^{a}$ que digan, que le digan $\| 4^{b}$ qué grande c. (falta oh), qué ermoza c. $\| 5^{a b}$ falta en las demás versiones orales. En el manus. crito se lee: Lo que arasta por enbaxo / 100 proves riqueserían $\| 6 a$ que el moro yeva, que yeva el moro $\| 6 b$ a las maravías $\| 7^{a}$ (que) se la 1 . X., quén se la 1 ., quén te lavró $\| 7^{b}$ Sorifá, Xerifé, la mi a. $\| 8 a$ Xerifé está $\| 8 b$ que la T., de T., que Franquía, de Franquía. Al v. 2 siguen, en una de las versiones orales, dos versos ajenos al romance:

$$
\begin{aligned}
& \text { Si unos parten para Fransia i otros para Turquia, } \\
& \text { con el más chico de eyos saludes yo le daria. }
\end{aligned}
$$

Quizá se relacionan con el romance de las Hermanas reina y cautiva (Catálogo, 48), especialmente la versión de A. GALANTE, "Quatorze romances judéo-espagnols", $R H i$, 10 (1903), 599, núm. viI, v. 2: "Unos parten para Francia, / otros para Turquía". Al cantarse el romance, suele repetirse el segundo hemistiquio de cada verso, menos el último. La voz $g^{i} u m a$ representa el ár. djum'a, quizá a través del turco cuma. La palabra árabe no sólo significa 'viernes', o sea el día de la 'asamblea general' de carácter religioso, sino también la misma salät del viernes. Ya en su suplemento a la Primavera y flor de romances (Antologia, 9, 401, nota ${ }_{2}$ ), Menéndez Pelayo suponía el significado '¿Aljama, mezquita?' La mayoría de nuestras informantes, así como la de Attias (p. 107, nota 3), identificaban $g^{i} u m a$ con el turco cami mezquita'. Favor (v. 3) significará 'pavor' (véase Rodolfo GIL, Romancero judeo-español, Madrid, Ioı1, p. 5; Antologia, 9, 395, nota 2), pero da lugar a que se cambie el sentido del verso en algunas versiones. La variante bafor, que figura en una sola versión, querrá decir 'jactancia, pomposidad': cf. esp. ant. baffar 'jactarse, baladronear' (Cantar de Rodrigo, ed. Menéndez Pidal, Reliquias de la poesia épica española, Madrid, 1951, v. 446) y hahareros 'fanfarrones, embusteros' (Libro de buen amor, I255c). Véase también DCEC, s. v. bravera y vaho. Es posible, por otra parte, pensar en port. bafo 'favor, protección'. La forma Xerifé (ofrecida por siete versiones orales) en vez de Xerifá (ár. šarif 'noble'; véase MENÁndez PIDAL, Romancero tradicional, 1, 34) refleja la armonía vocálica característica del turco, que rechaza la mezcla de vocales anteriores y posteriores en una misma palabra.

${ }^{10} \mathrm{La}$ versión del Catálogo (núm. 27) no incluye el texto que nos ocupa. Giménez Caballero, art. cit., p. 371, recogió en Escopia un brevísimo fragmento, inútil para nuestros propósitos, de este mismo romance de Miliselda y Don Gaifero.

11 Resulta curiosísima, en vista del significado de la voz giuma ('viernes, salät 
ni Menéndez Pelayo ni Attias se preocupan por identificar el texto que venimos estudiando ni por descubrir su origen ${ }^{12}$. He aquí la versión de Attias:
A la juma salió el moro, con trescientos caballeros, No los lleva por miedo,
a la juma el mediodía, que los lleva en compañía. ni por temor que tenía, sino que digan la gente: "OOh, que gran caballería!"
5 El caballo que el moro lleva, lo qu'arrastra por enbajo cien probes ricos facía. La toca que el moro lleva que se la labró la (e)sposa Al cabo de la su toca tiene una piedra zafira,
10 qu'arelumbra en la noche más que el sol de mediodía ${ }^{13}$.

del viernes'), la coincidencia con los siguientes versos de W., 173, antecedentes del romance sefardí de Miliselda y Don Gaifero (Menéndez Pelayo, Antología, t. 8, pp. $379,381)$ :

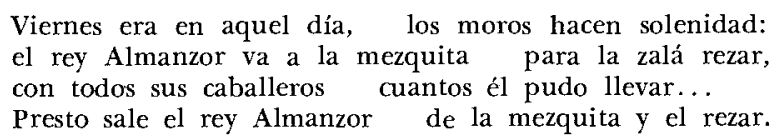

Si efectivamente estos versos guardan alguna relación con la mención de la $g^{i} u m a$, el texto "autónomo" de Rodas tendrá que haberse desgajado en algún momento de su vida tradicional de una versión del romance de Miliselda y Don Gaifero parecida a la de Salónica.

12 Tampoco ofrece nada Rodolfo Gil (núm. xxxv), quien reproduce el texto de Coello.

18 Romancero sefaradi, núm. 27 , vs. 31-50. Omitimos algunas indicaciones gráficas especiales. La numeración de los versos es nuestra. En el texto Coello-Menéndez Pelayo, que es más breve (núm. 9, vs. 15-22), los versos siguen el orden 1-4, 7, 9, 5, 6, y ofrecen las siguientes variantes: 1 De la giúma sale el $\mathrm{m}$., / de la giúma al m. d. \| $2, b$ que ll. su comp. \| $3^{a}$ llevaba $\| 4^{a}$ sinon porque \| $6 a$ arrastra por esfuelo $\|$ $6 b$ pobes [sic] r. hasía $\| 7^{b}$ es una rica romanía $\| 8$ falta $\| 9$ en la punta de la toca / lleva una p. safira || 10 falta.

Los versos finales de la versión de Attias, según él mismo observa, pueden reflejar una contaminación con el romance de Don Bueso (AtriAs, núm. 1): "En su cabeza lleva / una piedra zafira, // qu'arelumbra de noche / más que al mediodía". Ciertas versiones de Rodas y Esmirna ofrecen variantes aún más parecidas: "En la su kavesa, / una piedra zafira; // más alelumbra de noche / ke el sol a la mediodía". Hay ejemplos de fórmulas análogas en otros romances: "y entre almena y almena está una piedra zafira; // tanto relumbra de noche / como el sol a mediodía" (LARrEA, núms, 37-38; W., 179); "Castel Novo y Capuana, / Santelmo, que relucía, // aqueste relumbra entre ellos / como el sol de mediodía" (W., 101); "Por el val de las estacas / va Rodrigo a mediodia, // relumbrando van sus armas / como el sol de mediodía" (Romancero tradicional, t. 1, p. $7^{\circ}$, núm. 140 ; véanse también $14^{n}$, $\tilde{n}, p, q)$.

El tema romancístico de la piedra preciosa dotada de maravillosa luminosidad tiene su origen en abundantes modelos de la literatura medieval francesa (cf. Romancero hispánico, t. 1, 265-266 y nota 45). Representa un motivo folklórico muy difundido (STrth Thompson, Motif-index of folk-literature, rev. ed., Bloomington, Indiana, 1955-58: D 1645.1, Incandescent jewel). A los ejemplos ofrecidos por Menéndez Pidal pueden agregarse: Pèlerinage de Charlemagne, ed. E. Koschwitz, Leipzig, 1923, v. 423; Chrétien de Troyes, Erec, ed. W. Foerster, Halle, 189o, vs. 1614 var., 2378.16 var;; y Cligés, ed. W. Foerster, Halle, 1884 , 2750-2751. Es característico, por lo detallado y fabuloso, un pasaje de la Chanson d'Aspremont, ed. L. Brandin, Paris, 1924, vs. 7018, 7020 ss.: “Qatre escarboncles fist el pumel lever:.. / S'en est la terre et li païs si cler / a mie nuit, endroit le gal canter, / em poriés aseoir au disner / et as escés et as tables joër; / ja n'i estuet candelles alumer". 
Ofrece este poema indudable sabor de romance fronterizo. En esta clase de romances, notablemente propensos a la descripción detallada ${ }^{14}$, figuran como lugares comunes casi todos los elementos presentes en las dos versiones sefardíes que aquí reproducimos. Los romances fronterizos, al narrar las salidas y correrías de moros y cristianos, se detenían a describir con todo detalle la lujosa indumentaria de los caudillos. La atención del poeta recaía con frecuencia sobre alguna prenda valiosa ${ }^{15}$, hecha por la amada del guerrero con sus propias manos ${ }^{16}$. También se destacaba con admiración la extraordinaria valía de los caballos y solía aludirse a los jinetes que acompañaban al caudillo, los cuales eran a menudo "trescientos"17. He aquí algunos ejemplos:

Ya se salen de Jaén los trescientos hijosdalgo: ...

Un lunes por la mañana parten todos muy lozanos,

con lanzas y con adargas muy ricamente adrezados.

Todos visten oro y seda, todos puñales dorados:

¡muy bravos caballos llevan a la gineta ensillados!

Los jaeces son azules de plata y oro broslados;

las reatas son listones que sus damas les han dado (W., 82a).

Ya se salía el rey moro de Granada para Almería, [vars. partía, sale]

con trescientos moros perros que lleva en su compañía (W., 86). [var. caballeros]

De Granada parte el moro que Alatar se llamaba,...

caballero en un caballo que de diez años pasaba:...

una toca en su cabeza que nueve vueltas le daba:

los cabos eran de oro, de oro y seda de Granada;...

Sáleselo a recebir el maestre de Calatrava,

caballero en una yegua que ese día la ganara (W., 9o).

Cercada está Santa Fe con mucho lienzo encerado,

al derredor muchas tiendas de seda, oro y brocado...

1* "En los romances fronterizos suele haber descripciones bastante más detenidas [que en algunos otros tipos de romances]" (Menéndez Pidal, Romancero hispánico, 1, 66). Véase también F. López Estrada, La conquista de Antequera en el romancero y en la épica de los Siglos de Oro, Sevilla, 1956, p. 10; y B. González DE Escandón, "Notas estilísticas sobre los romances fronterizos", UnivZ, 22 (1945), 442-462.

${ }^{15}$ Según Ruth House Webber, Formulistic diction in the Spanish ballad, BerkeleyLos Angeles, 1951, p. 203, "The verses in which a maravilla is appended to a descriptive adjective appear chiefly in the poems dealing with Moorish subjects...' Las versiones de Abenámar (W., $78,78 a$ ) y el Romance de Portocarrero (véase Catálogo, 11) ofrecen varios ejemplos de ello, pero la verdad es que la expresión aparece con bastante frecuencia en muchos tipos de romances (cf. W., $5 a, 15,67,12.8,15^{1}$, $154 a, 193)$

${ }_{16}$ El nombre Xerifá de nuestro texto de Rodas nos recuerda los artificiosos romances moriscos en los que este nombre gozaba de tal popularidad que llegó a convertirse en un tópico. Así lo observó Lope de Vega: “...quedará celebrada en un libro de pastores, o la cantarán en algún romance, si de cristianos, Amarilis; si de moros, Xarifa; y el galán, Zulema” (La Dorotea, ed. J. M. Blecua, Madrid, 1955, p. 128).

${ }_{17}$ Cf. W., 81, 82a, 86, 88a-b. Claro que este número es un lugar común, no sólo en los romances fronterizos, sino en todo el romancero (W., 16, 18, 20, 29, 33, 50, $52,109,126,162,184,190)$ así como en la poesía épica: Cantar de mio Cid, 184, 186, 419, 605, 723, etc.; Los siete infantes de Salas (ed. Menéndez Prdal, Reliquias), pp. 193, 198, 199, 218; Cantar del cerco de Zamora, en Primera crónica general, pp. $499 b_{38}, 502 a_{24}$; Rodrigo (ed. Reliquias), vs. $403,871,994,1018$. 
cuando a las nueve del día encima un caballo negro El moro viene vestido y debajo esta librea un moro se ha demostrado y una lanza con dos hierros de blancas manchas manchado... y una adarga hecha en Fez de blanco, azul y encarnado, ae un muy fuerte jaco,

La mañana de Sant Joan gran fiesta hazen los moros rebolviendo sus cavallos, ricos pendones en ellas, y sus aljubas vestidas [ricos albornozes puestos El moro que tiene amores, y el que amiga no tiene, de acero muy bien templado, de un ante rico estimado (W., 93).

al punto que alboreava, por la vega de Granada, jugando iban a las cañas, labrados por sus amadas, de sedas finas y grana, texidos de oro y plata.] señales dello mostrava,

En el texto sefardí aparecen, pues, elementos tan típicos y tan comunes en el romancero fronterizo, que se dificulta bastante su identificación. Creemos, sin embargo, que los motivos que caracterizan el romance judeo-español aparecen combinados de modo muy semejante en un texto del siglo xvi. Se trata de un romance sobre la pérdida de Antequera, del que se conocen no pocas versiones antiguas. López Estrada (op. cit., pp. $7-19$ ) las clasifica en dos ramas: una forma "extensa" y otra "breve". Copiamos a continuación la primera parte del poema según las dos versiones. De la breve escogemos el texto del pliego suelto (s.l.n.a.) de Cristóbal Velázquez de Mondragón ${ }^{19}$; de la extensa citamos el texto según el Cancionero de romances impreso en Amberes sin $a \tilde{n} 0^{20}$. Ponemos en cursiva los elementos que aquí nos interesan:

18 Romance igual a W., 75. Preferimos en este caso las variantes publicadas por López Estrada, op. cit., pp. 2 I y 25 . Otro ejemplo, ya extremado, de estas tendencias descriptivas, es el romance "De Ronda sale el alcayde" (Menéndez Pelayo, Antologia, t. 9,28 ).

${ }^{19}$ Citamos la edición hecha por López EsTrada (op. cit. pp. 7-8), que se basa en el texto publicado en la Nueva colección de pliegos sueltos, ed. V. Castañeda y $\mathrm{A}$. Huarte, Madrid, 1933, pp. 63 ss. La glosa que sigue al romance en el pliego ofrece la variante "trezientos" para el v. 2o. López Estrada edita además otro pliego suelto de la misma versión breve, que se conserva en el British Museum (Aqui se contienen tres romances. El primero es el que dize: De Antequera salió el moro..., s.1.n. a.). Este texto difiere del de Velázquez en el orden de los versos (se asemeja más bien a la versión extensa) y presenta gran número de variantes que aquí no vienen al caso. El texto de Velázquez, según lo publica López Estrada, concuerda en general con el núm. 1044 de DuRÁN, aunque hay ligeras diferencias.

${ }^{20}$ Ed. Menéndez Pidal (Madrid, 1945), fols. $180 \mathrm{v}^{\circ}-182 \mathrm{v}^{\circ}$. Seguimos la transcripción hecha por López Estrada (op. cit., pp. 11-12). Corresponde a W., 74. Además de esta versión y las de Velázquez y del British Museum, tenemos noticia de los siguientes textos del romance (todos, excepto el núm. 5, citados por LópEz EsTrada, p. 12, nota 8, y p. 16, nota 16): 1) Primera parte de la Silva de varios romances, Zaragoza, 1550 , fols. $103 \mathrm{v}^{\circ}-105 \mathrm{v}^{\circ}$. Cf. variantes de W., 74, y LóPEZ EstradA, nota 8.-2) Miguel de Fuenllana, Libro de música para vihuela intitulado Orphénica lyra, Sevilla, 1554, fol. 145: "De Antequera sale el moro, / de Antequera se salía..." Cf. Menéndez Pelayo, Antologia, 9, 79, y Menéndez Pidal, Romancero hispánico, 2, 83 y $85 .-3$ ) Silva de varios romances, Barcelona, ${ }^{661}$ (reimpreso con un estudio preliminar de A. Rodríguez Moñino, Valencia, 1953), fols. 141-143.-4) Un pliego suelto: Aqui comiençan tres Romances... El tercero es el romance que dize de Antequera partio el Moro..., Granada, 1568. Cf. MENéndez Pidal, pról. al Cancionero, 


\section{VELÁZQUEZ}

De Antequera sale un moro, de Antequera aquessa villa. Cartas llevava en su mano, cartas de mensajería; escriptas ivan con sangre, y no por falta de tinta. El moro que las llevava, ciento y veinte años avía; ciento y veinte años el moro, de dozientos parecía. La barva llevava blanca, muy larga hasta la cinta; con la cabeça pelada la calva le reluzía; toca llevava tocada, muy grande precio valia; la mora que la labrara por su amiga la tenia. Cavallero en una yegua, que grande precio valia, no por falta de cavallos, que hartos él se tenia. Alhareme en su cabeça con borlas de seda fina. Siete celadas le echaron, de todas se escabullía. Por los campos de Archidona a grandes vozes dezia: - $\mathrm{S} \mathrm{Si}$ supiesses, el rey moro, mi triste mensajería, messarías tus cabellos y la tu barba bellida! Tales lástimas haziendo llega a la puerta de Elvira; vase para los palacios donde el rey moro bivía.

\section{Cancionero}

De Antequera partió el moro tres horas antes del dia, con cartas en la su mano en que socorro pedia; escritas ivan con sangre, mas no por falta de tinta. El moro que las llevava, ciento y veinte años avía; la barva tenía blanca, la calva le reluzía; toca llevava tocada, muy grande precio valia; la mora que la labrara por su amiga la tenia. Alhaleme en su cabeça con borlas de seda fina, cavallero en vna yegua, que cavallo no quería. Solo con un pajezico que le tenga compañia, no por falta de escuderos, que en su casa hartos avía Siete celadas le ponen de mucha cavalleria, mas la yegua era ligera, de entre todos se salía. Por los campos de Archidonia a grandes bozes dezía: - ¡O buen rey, si tú supiesses mi triste mensajería, messarias tus cabellos y la tu barva vellida! El rey, que venir lo vido, a recebirlo salia, con trezientos de cavallo, la flor de la morería.

p. xxix, y E. Porrbowicz,... Una colección de pliegos sueltos de Granada existente en la Biblioteca Universitaria [Jagellona] de Cracovia, Cracovia, 1891, p. 6, núm. 85 (obra poco asequible que hemos podido consultar gracias a la amabilidad de don José F. Montesinos).-5) Rosa española. Segunda parte de Romances de Joan Timoneda, s. 1., 1573. Cf. F. Wolf, Rosa de romances, o Romances sacados de las "Rosas" de Juan Timoneda, Leipsique, 1846 , p. viii, y variantes de W., 74--6) Otro pliego suelto: Signense tres romances. El primero. De Antequera dartio [sie] el moro..., s.l.n.a. Cf. F. WoLf, Ueber eine Sammlung spanischer Romanzen in fliegenden Blättern auf der Universitäts-Bibliothek zu Prag, Wien, 1849, p. 197, núm. Lix; R. Foulché-Delbosc, "Les Cancionerillos de Prague", RHi, 61 (1924), 326, núm. Lx; Menéndez Pidal, Cancionero, p. xxv (López Estrada, p. 16, nota 16, lo cita dos veces, como si se tratara de dos pliegos diferentes).-7) Otro pliego suelto: Aqui se contienen tres romances. El primero es el que dize: De Antequera salió el moro..., s.l.n.a. Cf. Durán, t. 1, p. lxx. Menéndez Pidal, Cancionero, p. xxviii, lo da por desconocido. No cabe duda de que es idéntico, o por lo menos muy parecido, al texto del British Museum, según observa López Estrada, p. 16, nota 16.-8) Una versión de la tradición local de Antequera: "De Antequera salió el moro / por la cueva de Albarizas..." Cf. López Estrada, p. i7, nota 16. 
Encontrado a con el rey, que del Alhambra salia, con dozientos de a cavallo, los mejores que tenia. Ante el rey, cuando se halla, tales palabras dezía:

-Mantenga Dios a tu alteza, salve Dios tu señoría...
-Bien seas venido, el moro, buena sea tu venida. -Alá te mantenga, el rey, con toda su compañia...

Notables nos parecen las semejanzas que se advierten entre estas versiones antiguas y los textos sefardies de Rodas y Salónica. La rima asonante es la misma, y en varios casos se emplean idénticas palabras: dia ${ }^{21}$, compañia, tenia, cavalleria, valia. Además, tienen buen número de motivos comunes: I) la salida del moro; 2) el gran valor del caballo o yegua (Velázquez, v. 10 y Salónica); 3) la valiosa toca; 4) labrada por la amiga del moro; y 5) la presencia de los trescientos caballeros que le acompañan. Las palabras "no es por compañía..." o "no los lleva por miedo..." nos hacen pensar en las frases negativas que tanto abundan en las versiones antiguas: "no por falta de tinta", "no por falta de caballos", "no por falta de escuderos". El verso "Lo que él arrastra por embaxo, / sien (mil) proves ricos fazia" "22, quizá sea un eco del alhareme con sus "borlas de seda fina". Cierto que en las versiones antiguas el moro sale solo, mientras que en los textos sefardíes va acompañado de un gran séquito. Sin embargo, este cambio no es difícil de explicar: se trata de uno de esos casos de simplificación tan característicos de la tradición oral. En el texto sefardí deben haberse fundido en una sola las dos salidas que se encuentran en la versión antigua. Así se convierten en compañeros del moro mensajero los "trezientos de cavallo" que originalmente iban guardando al rey, ya ausente de la escena o identificado a su vez con el moro.

Si admitimos que el Romance de Antequera es la fuente de los textos sefardies, podremos apreciar, también en este caso, la radical reducción sufrida por el romance antiguo. Nada queda de la trama original, y se ignoran las circunstancias en que sale de hacer sus rezos el desconocido moro. Sólo permanece la rica y colorida descripción inicial del árabe de Antequera, mensajero de tristes nuevas para el rey de Granada y peregrino multisecular en la tradición oral sefardi ${ }^{23}$.

Samuel G. Armistead Joseph H. Silverman

University of California, Los Angeles.

${ }^{21}$ Al precisar que la salida se efectúa al mediodía, la versión sefardí recoge una fórmula favorita del Romancero, que gusta de buscar mayor dramatismo situando los acontecimientos en horas extremas: ya a medianoche (W., 69, 174, 190; Catálogo, 74; Attias, 52), ya al mediodía (W., 31; Antologia, 9, pp. 34, 9o; Catálogo, 2; y el texto de Romancero tradicional citado en nuestra nota 13). Por lo demás, la djum'a se celebra de hecho al mediodía.

${ }^{22}$ La frase del segundo hemistiquio es fórmula que se encuentra en otros textos. Cf. la versión de la Muerte del Duque de Gandia que publica A. Galante (núm. Iv, v. 8): "Cien proves ricos haría"; en una versión nuestra inédita de Çanakkale (Turquía); "sien povres ricos azía"; y en Atrias, núm. 35: "cien probes ricos s"hacían".

${ }^{23}$ La descripción del moro también parece haber influido en otro romance sefardí. Los versos siguientes sirven de prólogo a dos versiones de La dama del conde Alemán 